\title{
Seedling Blight of Festuca arizonica Caused by Rhizoctonia solani
}

\author{
Mopuri N. Reddy ${ }^{1}$, Stanley H. Faeth ${ }^{2}$
}

${ }^{1}$ Department of Applied Microbiology, S P Mahila Visvavidyalayam, Tirupati, India, ${ }^{2}$ Department of Biology, University of North Carolina at Greensboro, Greensboro, USA.

Email: mopuri_nr@yahoo.com

Received August $12^{\text {th }}, 2010$; revised October $28^{\text {th }}, 2010$; accepted November $3^{\text {rd }}, 2010$.

\begin{abstract}
We report here a damping-off disease occurring at the seedling stage of the grass Festuca arizonica (Arizona fescue) that is caused by the soil-borne fungal pathogen Rhizoctonia solani.
\end{abstract}

Keywords: Damping-off, Endophytes, Festuca Arizonica, Rhizoctonia Solani

\section{Introduction}

Festuca arizonica (Vasey) or Arizona fescue (Pooideae) is a perennial bunch grass native to Arizona, Nevada, New Mexico and Colorado in the U S A and in Northern Mexico [1]. Arizona fescue grows in semi-arid grasslands at the elevations between $2300 \mathrm{~m}$ and $3200 \mathrm{~m}$. It has been studied extensively with regards to its association with the asexual and systemic fungal endophyte Neotyphodium and how the endophyte alters host growth and reproduction and resistance to herbivores and pathogens [2-4]. Although this native grass is important as forage grass and in ecological studies, little is known about the diseases occurring on this plant.

Rhizoctonia solani is one of the most common soilborne fungal pathogens, ubiquitous in nature and exhibits a strong saprophytic ability, a high degree of pathogenicity and a wide host range. $R$. solani can infect seeds, seedlings or adult plants. When seeds are infected, they may fail to germinate. If infected seeds germinate, then the young seedlings may fall over at the soil line because $R$.solani first infects the hypocotyls as the seedling emerges to the surface of the soil or infects the stem at the soil line.

Here, we report a damping-off disease occurring at the seedling stage that is caused by the soil-borne fungal pathogen Rhizoctonia solani.

\section{The Disease}

In experimental plots of Festuca arizonica some of the seedlings were observed to show damping-off symptoms about two weeks after emergence. Infected seedlings occurred as scattered plants among apparently healthy seedlings. Infected seedlings were lifted out carefully, gently washed and observed for symptoms.

The hypocotyls of infected seedlings showed initial water-soaked lesions which gradually turned dark brown reddish brown and become sunken and dry, girdling the hypocotyls at or near the surface of the soil and ultimately resulting in the total collapse of the seedlings (Figure 1). The seedlings gradually become chlorotic and collapsed. On older seedlings, the rotting extended downward, killing the tap root and lateral roots (Figure 2).

Repeated isolations and inoculation studies showed that

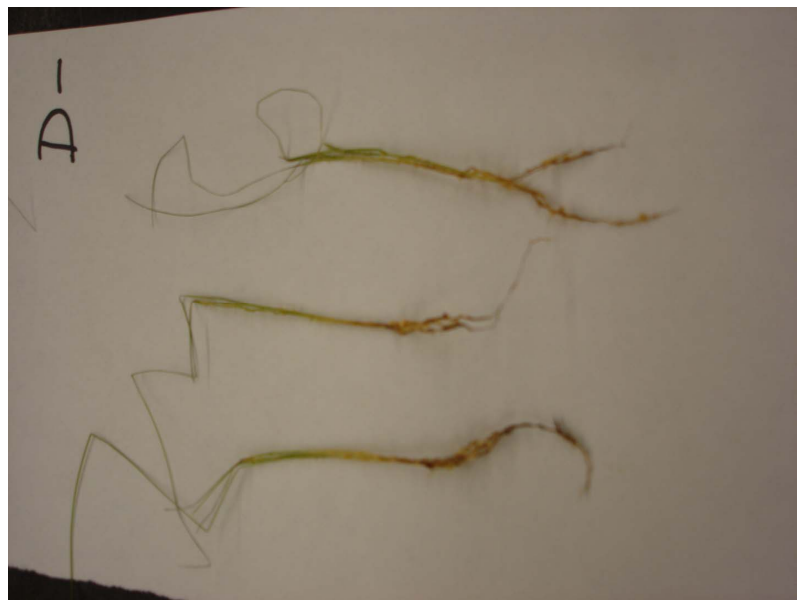

Figure 1. Arizona fescue seedlings showing water-soaked symptoms on hypocotyls at initial stages of infection. 


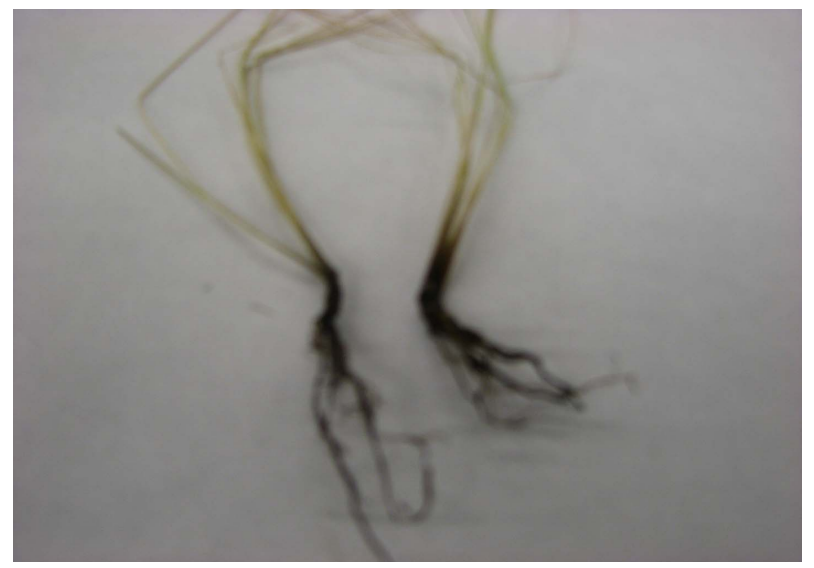

Figure 2. Characteristic dark brown, sunken lesions at later stages of infection on the hypocotyls, including rotting of the tap root and root laterals and the collapse of the seedlings.

Rhizoctonia solani Kuehn was primarily responsible for the disease. Pathogenicity of the isolate was proved by following the Koch's Postulates. The pathogen was grown on $3 \%$ oatmeal-sand medium in $250 \mathrm{ml}$ Erlenmeyer flasks for 10 days. The inoculum was thoroughly mixed with the top $5 \mathrm{~cm}$ of soil in pots in the green house. Healthy 10 day old $F$. arizonica seedlings were transferred to the pots and observed periodically for disease occurrence. Some of the pots contained Neotyphodiuminfected seedlings while others contained endophyte-free seedlings. Typical disease symptoms on healthy seedlings appeared 5 days after inoculation. The total maturation of lesions and collapse of the seedlings occurred about three weeks after inoculation. The disease occurrence and seedling loss was greater for seedlings of grass genotypes without endophyte infection than those infected by Neotyphodium. This suggests that endophyte infection may suppress $R$. solani infection or disease intensity. Because the effects of endophytic infection on the seedling diseases are not well-studied [3], R. solani may be a good candidate for studies that test how endophyte infection alters pathogen resistance in Arizona fescue.

The culture was maintained on PDA with periodical transfers. The fungus produced cottony mycelial growth, with brown to dark brown round to irregular sclerotia on the medium. The identity of the pathogen as Rhizoctonia solani Kuehn was via standard morphological and cultural characteristics as suggested by Parmeter [5] by comparison with to a $R$. solani reference culture. Culturing surface sterilized seeds of $F$. arizonica on water agar and on Rhizoctonia specific medium showed growth of the fungus from the seeds. Thus, $R$. solani may be seedborne and may be transmitted vertically to seedlings, similar to Neotyphodium endophytes, in addition to horizontal transmission to seedlings in the soil.

A search of the literature to date in Biological Reviews, Phytopathology, USDA Hand Books, and Rhizoctonia specific monographs and reviews revealed no reports of occurrence of damping-off caused by Rhizoctonia solani on F. arizonica. Therefore, this paper may be considered as the first report of this fungal disease on F. arizonica.

\section{Acknowledgements}

The authors are indebted to Sally Wittlinger for technical assistance. Support was provided by the School of Life Sciences, Arizona State University, Tempe USA to Prof. M. N. Reddy, as Visiting Professor and by NSF Grants DEB 0613551 and 0917741 to S.H.F.

\section{REFERENCES}

[1] United States Department of Agriculture, "Range Hand Book,” Dover Publications, New York, 1988.

[2] F. M. Schulthess and S. H. Faeth, "Distribution, Abundances, and Associations of the Endophytic Fungal Community of Arizona Fescue (Festuca arizonica)," Mycologia, Vol. 90, No. 4, 1988, pp. 569-578. doi:10.2307/3761215

[3] G. P. Cheplick and S. H. Faeth, "The Ecology and Evolution of the Grass Endophyte Symbiosis,” Oxford University Press, UK, 2009.

[4] S. H. Faeth and T. J. Sullivan, "Mutualistic Asexual Endophytes in a Native Grass are Usually Parasitic,” The American Naturalist, Vol. 161, No. 2, 2003, pp. 310-325. doi:10.1086/345937

[5] J. R. Parmeter Jr., "Rhizoctonia Solani," University of California Press, Berkeley, 1970. 